\title{
CONSTITUCIÓN Y DERECHOS HUMANOS ${ }^{1}$ Constitution and Human Rights
}

\author{
Alvaro Salgado González²ํㅗㄴ
}

Fecha de recepción: 15 de marzo de 2017

Fecha de aceptación: 04 de mayo de 2017

Sumario: 1. Introducción; 2 Causas de justificación: Autorizaciones o normas;

3. Constitución y normas preventivas de la pena; 4. Conclusiones;

\section{Referencias Bibliográficas.}

\footnotetext{
${ }^{1}$ Este artículo es producto del trabajo investigativo realizado dentro de las actividades del semillero de investigación GerminaciónTutela Penal, adscrito al grupo de investigación Filosofía del Derecho, Derecho Internacional y Problemas Jurídicos Contemporáneos, de la Facultad de Derecho y Ciencias Políticas de la Universidad de Cartagena.

${ }^{2}$ Abogado, Universidad de Cartagena. Especialista en Ciencias Penales y Criminológicas de la Universidad Externado de Colombia. Magister en Derecho Penal de la Universidad de Salamanca en convenio con La Universidad Santo Tomás de Colombia. Docente de Derecho Penal de la Universidad de Cartagena.
} 


\section{CÓMO SE CITA ESTE ARTÍCULO (Normas APA-6)}

Salgado González, Alvaro (2017). Constitución y Derechos Humanos. Revista Jurídica Mario Alario D'Filippo, IX (18), pág 21-30.

\section{RESUMEN}

El presente artículo busca definir la relación existente entre la normatividad constitucional y la articulación de la ley penal en el sistema jurídico colombiano. En su desarrollo, se realizó un análisis sistémico universal y descriptivo de aquellas normas de carácter superior que derivan en principios y fundamentos propios de la codificación penal. Se busca con ello definir, de manera clara, cómo la constitucionalización del sistema jurídico y la aplicación de principios universales propios del derecho internacional, influyen en la naturaleza tanto fáctica como teórica de la normatividad penal.

\section{PALABRAS CLAVE}

Constitución, Derechos Humanos, Norma, Ley, Estado Social y Democrático de Derecho.

\section{ABSTRACT}

This article seeks to define the relationship between constitutional norms and the articulation of the criminal law in the Colombian legal system. It develops a universal and descriptive systemic analysis of those superior provisions that turn into principles and foundations of the criminal codification. This seeks to clearly define how the constitutionalization of the legal system and the application of universal principles of international law influence both the factual and the theoretical nature of the criminal law.

\section{KEYWORDS}

Constitution, Norm, Law, Social and Democratic Law State, Human Rights. 


\section{INTRODUCCIÓN}

La Constitución moderna, vista desde una perspectiva de análisis de naturaleza universal, configura en sí misma los lineamientos dogmáticos en los que descansan una multiplicidad de valores, principios y derechos, los cuales han de servir como criterios de orientación necesarios para la conformación de cualquier Estado democrático moderno. Naturalmente, esto no se refiere a un concepto de dogma como un sistema de carácter cerrado e inmutable, sino a una sistematización integrada de carácter abierta y progresista de elementos fundamentales y esenciales que son el soporte y razón misma de ser del Estado. La Constitución colombiana de 1.991, inspirada en un Estado Social y Democrático de derecho, no es la excepción; en efecto, en su artículo 4으 deja plasmado un sistema de alternativas filosóficas y de conceptos de derecho.

Ya desde 1.981 la Corte Suprema de Justicia ha venido sosteniendo que la Constitución Política no sigue ni exige seguir a escuela alguna de derecho penal; ello permite que en la elaboración de los códigos penales las únicas limitantes de su normativa sean aquellas que se disponen en el ordenamiento constitucional superior; esto es, en relación con lo que manda, permita y no prohíba el código.

Esta línea de pensamiento fue acogida por la Constitución de 1.991; es decir, que ésta tampoco adoptó ninguna escuela penal como propia ${ }^{3}$. Después la Corte Constitucional reconoce que la Constitución Política contiene aspectos penales sustantivos y procedimentales; inclusive se resaltan valores y postulados especialmente en lo que tiene que ver con derechos fundamentales ${ }^{4}$, lo que definitivamente apunta hacia el derecho penal, porque igualmente lo orientan y ubican en su alcance.

Si bien la Constitución Política no es un compendio de dogmas, cabe resaltar que su estructura -vista desde una perspectiva sistémica e integral- permite que, atendiendo su inspiración filosófica y la relación normativa constitucional con el ámbito del derecho penal, pueda contener normas que se deriven y fundamenten la razón de ser de un código de tal naturaleza. En efecto, el Código Penal colombiano, en su parte general libro primero, consagra las normas rectoras de la ley penal y dispone, en su artículo 13: "La normas rectoras contenidas en este Código constituyen la esencia y orientación del sistema penal. Prevalecen sobre las demás e informan su interpretación" (Congreso de la Republica de Colombia [C.R.C], 2000).

Las normas rectoras del Código Penal colombiano prevalecen sobre las demás normas que integran la totalidad de la normativa penal. Esta superioridad de las normas rectoras deriva directamente de la integración de postulados y normas sobre derechos humanos que se encuentran consignados, de manera explícita e implícita, tanto en la Constitución

\footnotetext{
3 Sentencia C-599 del 10 de diciembre de 1.992,M.P. Fabio Morón Díaz

4 Sentencia C-038 del 9 de febrero de 1.995,M.P. Alejandro Martínez Caballero
} 
Política como en los tratados y convenios internacionales ratificados por Colombia. Estos últimos constituyen lo que se denomina bloque de constitucionalidad. El artículo 2은 Superior integra a la normatividad penal el llamado bloque de constitucionalidad, el cual desde el punto de vista constitucional es una importante herramienta que permite lograr un efecto conglobante en la interpretación y aplicación de la ley penal fundamental.

El 10 de diciembre de 1.948, la Asamblea General de las Naciones Unidas promulgó en París la Declaración Universal de Derechos Humanos,

(...) como ideal común por el que todos los pueblos y naciones deben esforzarse, a fin de que tanto los individuos como las instituciones, inspirándose constantemente en ellas, promuevan mediante la enseñanza y la educación, el respeto a estos derechos y libertades" (ONU, 1948).

Desde 1.950 comienzan a nacer sistemas regionales de protección de derechos y libertades fundamentales. El primer sistema regional de protección de derechos surge en Europa occidental con la Convención Europea de Derechos Humanos, suscrita en Roma el 4 de noviembre de 1.950 y en vigor desde el 3 de septiembre de 1.953.El segundo sistema regional es el de América Latina, con la Convención Americana sobre Derechos Humanos, suscrita en San José (Costa Rica) el 22 de noviembre de 1.969, y complementada con un protocolo que prohíbe la pena de muerte y otro que protege los derechos económicos, sociales y culturales.

De lo anotado, se puede afirmar que la Constitución Política y el bloque de constitucionalidad son la esencia y razón de ser de la existencia del derecho penal. Por eso, antes que hablar de dogmática es mejor hablar de derechos humanos y de Constitución, porque son principios universales que pertenecen a todos los hombres, como la vida, la dignidad, la igualdad, la libertad, la intimidad personal y familiar, la libertad de conciencia, la libertad de cultos, la presunción de inocencia, el debido proceso. Hablar de derechos humanos, es reconocer que las normas de cultura deben ser congruentes con ellos, por cuanto son postulados de conducta, o si se quiere valoraciones que se le asignan a los comportamientos; por eso son individuales, grupales y del medio ambiente. En fin, podemos decir que los derechos humanos son las herramientas que se utilizan para dignificar al ser humano.

\section{CAUSAS DE JUSTIFICACIÓN: AUTORIZACIONES O NORMAS}

Detrás de los ordenamientos penales se encuentran normas de comportamiento, las cuales son de gran importancia para lograr la convivencia de los ciudadanos, y por lo mismo, están provistas de sanciones. Cada conducta punible describe las diferentes formas de delitos. La tipicidad permite afirmar que el tipo, que es uno de los elementos constitutivos de ésta, contiene el injusto. La tipicidad está conformada por los elementos 
del injusto que edifican una concreta clase de delito; es por esto que llama la atención que aún se esté debatiendo que, comprobada la tipicidad, deba hacerse el estudio de la antijuridicidad, ya que el análisis inicial conlleva a considerar que si el comportamiento es contrario a derecho y la respuesta es afirmativa, surge el injusto. Si de la antijuridicidad surge el injusto, y está de por medio una causal de justificación, obviamente que no hay injusto, y por lo tanto, la no estructura de la conducta llega hasta esta sede, y por consiguiente la tipicidad de la acción debería implicar la antijuridicidad.

Sobre este tema, tendría que pensarse en hacer el análisis de la estructura de la conducta punible cuando no surja el injusto directamente en sede de la antijuridicidad, precisamente porque si se actúa conforme a derecho ¿para qué realizar un análisis de la tipicidad?

La antijuridicidad puede excluirse, pues sabido es que un comportamiento típico puede justificarse; ya que bajo ciertas condiciones, existen acciones que se encuentran prohibidas y que son merecedoras de pena, pero pueden darse ciertas circunstancias concretas que permitan su realización, como por ejemplo la legítima defensa.

Para excluir la antijuridicidad de acciones típicas se debe tener en cuenta que el ordenamiento no solo son prohibiciones, sino también autorizaciones que hacen posible que estas últimas puedan ser desplazadas en determinadas circunstancias. Las autorizaciones entonces se tornan permisivas, por lo que dejan de ser tipo de injusto para convertirse en tipos de justificación. Es así que cuando está presente una causa de justificación, la norma prohibitiva que se encuentra contenida en el tipo de injusto pierde la esencia de deber jurídico.

Las causales de justificación son proposiciones jurídicas autónomas cuya verdadera razón de ser no consiste en justificar algo prohibido, sino que autónomamente tiene un fin propio de mayor proyección: la protección manifiesta de la naturaleza del derecho, en situaciones como la legítima defensa, la ejecución de la pena en una sentencia, obrar en legítimo ejercicio de un derecho, de una actividad lícita o de un cargo público. En casos como estos, estamos frente a normas que son independientes, en las que prevalece la causa de justificación sobre la norma prohibitiva. Cuando se realizan sus requisitos, por tanto, surge un comportamiento atípico que impide hacer emerger en él la situación fáctica concreta, el mandato correspondiente al tipo de injusto.

De lo dicho, se puede colegir que los tipos penales son reglas que contienen excepciones, manifestadas en las causales de justificación que se configuran de manera exclusiva cuando se desarrollan presupuestos atípicos en la conducta típica. Lo principal, lo que se expresa como regla general, es la obediencia de la norma; es por esto que se dice que la tipicidad es indicio de la antijuridicidad, lo que nos conlleva a tener en cuenta que cuando se realiza el tipo se fundamenta la antijuridicidad, salvo que excepcionalmente no esté de presente una causal de justificación. 
La relación entre los conceptos de norma prohibitiva y proposiciones permisivas se ha tomado como fundamento del cual depende la validez de la concepción imperativa de la norma. Bajo Fernández $z^{5}$, siguiendo los postulados de Bockelmann, sostiene que la existencia separada de normas permisivas frente a las normas prohibitivas pone de manifiesto que no todas las normas penales son imperativas, pues la permisión no implica en sí misma imperativo alguno. Mir Puig se aparta de este planteamiento, y niega que las proposiciones jurídicas en las que se prevén causas de justificación constituyan normas independientes; al respecto, dice:

Personalmente, en cambio he combatido este planteamiento negando que las proposiciones jurídicas en las que se prevén causas de justificación constituyan normas independientes: a mi juicio son disposiciones complementarias, limitadoras del imperativo que se desprende de las proposiciones jurídicas que definen las figuras del delito. La norma penal completa se forma de la puesta en relación de ambas clases de proposiciones jurídico penales. (Puig, 1976, p.31)

Y agrega:

Ello no obsta a la posibilidad de que, a su vez, las proposiciones permisivas encierran en sí mismas otras normas imperativas, lo que sucede cuando la causa de justificación no solo permite realizar el tipo (positivo), sino que expresa el deber de hacerlo (p.ej: cumplimiento de un deber). En este caso la función complementaria de limitar el imperativo de la prohibición penal tiene lugar mediante el establecimiento de otro imperativo. Pero ello no es necesario, (piénsese en la legítima defensa o en el estado de necesidad, que se limitan a crear facultades, no deberes), lo que prueba que lo especifico de la función de permisión es solo limitar el imperativo penal. (Puig, 1976, p.31)

\section{CONSTITUCIÓN Y NORMAS PREVENTIVAS DE LA PENA}

El Código Penal colombiano (Ley 599/2000) señala dos normas rectoras que constituyen el enunciado en tanto a los principios de las sanciones penales (art.3ㅇ) y las funciones de la pena (art.4ㅇ). Los principios de necesidad, proporcionalidad y razonabilidad de la pena, que operan tanto a nivel del proceso legislativo como del judicial fueron reconocidos por la Corte Constitucional al poner de presente que en ejercicio de la facultad punitiva del Estado, "el legislador debe propender a la realización de los fines sociales de Estado, entre ellos los de garantizar la efectividad de los principios, derechos y deberes consagrados en la Constitución y de asegurar la vigencia de un orden justo..." (Corte Constitucional de Colombia [C.C.C], 1.996). En materia penal, la potestad legislativa de tipificación está sometida al control constitucional de las medidas, según la aptitud para la protección del bien jurídico tutelado, la necesidad de esa protección específica en contraste con otros medios preventivos igualmente idóneos y menos restrictivos de la libertad" ([C.C.C], 1996).

5 Miguel Bajo Fernández. Algunas observaciones sobre la teoría de la motivación de la norma. Estudios penales. Eds. Fernández Albor y Santiago de Compostela, 1.977.p18 
Esta pena, dice el artículo 4을 citado, debe cumplir funciones de prevención general, retribución justa, prevención especial, reinserción social y protección al condenado. En este punto no debe pasarse por alto, pues entraría la normatividad penal en contradicción con la naturaleza misma del Estado Social y Democrático de derecho, en el cual, la pena tiene como una de sus funciones la retribución justa, por cuanto la amenaza de la pena es diferente a la venganza que es lo que traduce el concepto de retribución, del cual se deriva que ninguna venganza es justa. Cuando el hombre cede al Estado parte de su libertad en tanto su razón de ser óntico a la naturaleza, para convivir en armonía con sus congéneres, lo hace para hacer posible el intercambio esencial que constituyen las relaciones sociales, sin las cuales no habría armonía, sino caos. Y si falta a los deberes que la sociedad le impone, debe sometérsele a un proceso justo, y como epílogo a una pena, pero no para tomar venganza por lo que hizo, sino como mecanismo de prevención general y especial para los que forman parte del conglomerado social.

Sobre este planteamiento, la Corte Constitucional expresa: "La pena tiene en nuestro sistema jurídico un fin preventivo, que se cumple básicamente en el momento del establecimiento legislativo de la sanción, la cual se presenta como la amenaza de un mal ante la violación de las prohibiciones..." (Corte Constitucional de Colombia [C.C.C], 1993). En esta misma decisión, la Corte Constitucional -en posición que no compartimossostiene acogiendo sin reservas el contenido total del artículo 4으 del Código Penal, que el fin de la pena es también retributivo, el cual "se manifiesta en el momento de la imposición judicial de la pena" (C.C.C, 1993). A nuestro juicio, retribución implica venganza (vindicta), que nos remite indefectiblemente a la ley del talión, de nefasta recordación. Cuando se impone la pena, se está siendo consecuente con la prevención general y aun con la especial, pero ello no constituye retribución, sino la imposición de una pena justa y proporcionada al daño causado.

Si compartimos que la norma es subyacente, y la ley es objetiva, débese concluir que el sujeto no viola la ley cuando actúa de manera contraria a lo que ésta prohíbe, sino que se ubica en ella, por cuanto se apartó del deber de no afectar bienes jurídicos, que es la parte subyacente, y precisamente es esa la razón de ser de la imposición de la pena. Dicho de otra manera, la protección de bienes jurídicos es la fundamentación de nuestro sistema penal (Roxin, 1997), en contraposición a la protección de normas (Jacobs, 1997). En 1.996 la Corte Constitucional da un giro en su doctrina y señala que se muestra acorde con la norma rectora (artículo 4으 C.P.), en cuanto establece que la pena tiene un fin preventivo y también retributivo, pero agrega:

La definición legislativa de las penas en un Estado de derecho no se orienta por fines retributivos rígidos, sino por objetivos de prevención general, esto es, debe tener efectos disuasivos; y que en este mismo modelo de Estado, fundado en la dignidad humana, la ejecución de las penas debe tener una función de prevención especial positiva; es decir, en esta fase se debe buscar ante todo la resocialización del condenado. (Corte Constitucional de Colombia [C.C.C], 1996) 
No embargante, la Corte Constitucional, en diversos pronunciamientos, ha continuado incluyendo la retribución como uno de los fines de la pena, entendiendo por tal el momento de la imposición judicial de la pena, aspecto este que a nuestro juicio debe ser definitivamente revisado a nivel de la misma ley. Ya en el año 2.002 enfáticamente la corte afirma:

Solo son compatibles con los derechos humanos penas que tiendan a la resocialización del condenado, esto es a su incorporación a la sociedad como un sujeto que la engrandece, con lo cual además se contribuye a la prevención general y la seguridad de la coexistencia, todo lo cual excluye la posibilidad de imponer la pena capital. (Corte Constitucional de Colombia [C.C.C], 2002)

La prevención general constituye la conminación abstracta que se hace a través de los tipos, en tanto que la especial apunta a la etapa de ejecución de la pena. Pero ambas convergen cuando el funcionario judicial la impone, pero con mayor énfasis la prevención general, en cuanto tiende a demostrar que la amenaza del mal que se pone de presente en el proceso de adecuación típica efectivamente se cumple.

Comentario particular merece la dificultad para demostrar la prevención especial en las medidas de seguridad de carácter socioterapéutico, ${ }^{6}$ que han dado lugar a que dicha prevención se desplace a la llamada prevención general positiva, a la cual se atribuyen tres finalidades y efectos distintos: un efecto didáctico, en cuanto al ejercicio de la finalidad al derecho; un efecto de confianza, si el ciudadano ve que el derecho prevalece; y un efecto de satisfacción, si con la sanción por el quebrantamiento del derecho se considera apaciguada la conciencia jurídica general y concluido el conflicto con el autor. Estas tres finalidades en su conjunto podrían denominarse prevención de integración.

Pero todo parece indicar que la Corte Suprema de Justicia armoniza la prevención general con la especial. Así se puede observar en la Sentencia 15003 del 31 de agosto del año $2.001^{7}$, en la que se enfatiza que la utilidad de la pena supone la necesidad social de la misma, y en caso contrario resultaría inútil, e imponerla constituiría una ostensible injustica, o en el regreso a la ley del talión, que suponía la razón de ser de la pena como un castigo para devolver un mal con otro. Dicho de otra manera, el Estado utilizaría su poder como un instrumento de violencia y venganza con respecto al individuo.

6 Corte Suprema de Justicia.Cas.Penal. Sentencia 15610 del 18 de sep.2001.M.P. Fernando Arboleda Ripoll

7 “ En tal virtud el pronóstico al que se condiciona el reconocimiento de la pena sustitutiva, por sujetarse a su vez al entorno laboral, personal, familiar o social del sentenciado, ha de conciliar el sentido y fines de la pena de modo que en estos pueda armonizarse la prevención general y la especial, pues si bien es tan legítimo que, en adecuado sistema de política criminal que orienta aquella función con arreglo a los principios de protección delos bienes jurídicos, proporcionalidad y culpabilidad, el derecho penal está llamado a desempeñar una labor profiláctica en abstracto, no menos lo es que, dados los presupuestos de garantía de los derechos del procesado, también se encuentra orientado a cumplir una función de prevención especial, pero no en el sentido negativo bajo el falso entendido de que existen delincuentes irrecuperables que seguramente volverán a reincidir, sino en otro contrario en que, de manera positiva y dentro del respeto por la autonomía y dignidad del condenado se propenda hacía su resocialización" 
Frente a la prevención general y atendiendo el contexto constitucional, la prevención general debe estar fundamentada por una concepción humanista de la ley, que encuentra su inspiración en el artículo 1을 Superior constitucional, en el que se destaca y resalta la dignidad humana como fundamento de todo el ordenamiento jurídico del Estado. La prevención general además está cimentada en el Estado Social y Democrático de derecho y en el principio de proporcionalidad, como consecuencia sistematizada de varias disposiciones de la Constitución Política que compendian todo el ordenamiento, con marcada proyección sobre la legislación penal.

De manera que los conceptos de prevención general y prevención especial están íntimamente relacionados con el concepto de norma. Se tiene en primer lugar al Estado que se orienta y enmarca para su funcionamiento en la Constitución Política, y en el caso nuestro su esencia es la de Social y Democrático de Derecho. En segundo lugar, la norma superior definitivamente plasma los derechos fundamentales y a su vez deja claro que toda la fundamentación penal y procesal penal encuentra su respaldo en ella, aunque por su esencia general y político no describe delitos ni sanciones, pero ello no es óbice para aceptar que su contenido de política criminal permita concluir que en ella se encuentre la estructura principal del sistema penal. Es por ello que la Constitución Política es la más importante fuente formal de derecho. En los Estados democráticos se tiene como norma de normas, aspecto este que para el nuestro no es la excepción, como se observa en el artículo 4은 Superior.

\section{CONCLUSIONES}

Si nuestro sistema penal se encuentra dogmáticamente enmarcado en la protección de bienes jurídicos, a ellos se refiere el concepto de normas jurídicas, por cuanto el postulado de comportamiento se origina en el poder público. Se ha dicho que no deben asimilarse los postulados de norma y ley como una sinonimia de derecho positivo, como en el caso del comportamiento que esperamos de una persona en determinadas situaciones.

Objetivamente, con Kelsen, podría pensarse así, pero el análisis debe ir mucho más allá, sin perder de vista que el postulado de conducta emerge de la vida social de un pueblo. En tanto la ley, es la manifestación objetiva de la voluntad del Estado. La norma entonces, depende de las relaciones sociales, mientras que la ley es la materialización de un ordenamiento o de una prohibición objetivada. Tiénese, por consiguiente, que el derecho no es solamente la ley, y por lo mismo la ley no es la pura voluntad del poder político. Lo que subyace -la norma- es lo que impone el contenido de valoración existente antes de ubicarse el infractor en la ley, y una vez ello sucede, el Estado cumple la amenaza de imponer una pena. De verdad que no se ve en qué forma podría fundamentarse la imposición de la pena, a no ser que definitivamente se reconozca y se acepte que es por quebrantar o poner en peligro bienes jurídicos tutelados. 


\section{REFERENCIAS BIBLIOGRAFICAS}

Corte Constitucional de Colombia. (1992). Sentencia C-599. Recuperado de: http://www. corteconstitucional.gov.co/relatoria/1992/C-599-92.htm

Corte Constitucional de Colombia. (1995). Sentencia C-038. Recuperado de: http://www. corteconstitucional.gov.co/relatoria/1995/C-038-95.htm

Corte Constitucional de Colombia. (1996). Sentencia C-070. Recuperado de: http://www. corteconstitucional.gov.co/relatoria/1996/C-070-96.htm

Corte Constitucional de Colombia. (1996). Sentencia C-430. Recuperado de: http://www. corteconstitucional.gov.co/relatoria/1996/c-430-96.htm

Corte Constitucional de Colombia. (2002). Sentencia C-802. Recuperado de: http://www. corteconstitucional.gov.co/relatoria/2002/C-802-02.htm

Corte Suprema de Justicia Sala de Casación Penal. (2001). Sentencia 15610. Recuperado de: https://corte-suprema-justicia.vlex.com.co/vid/n-supremapenal-18-septiembre-2001-44191288

Fernández, M. (1997). Algunas observaciones sobre la teoría de la motivación de la norma. España, Santiago de Compostela: Eds. Fernández Albor y Santiago de Compostela.

Jakobs, G. (1997). Derecho penal: parte general: fundamentos y teoría de la imputación. España, Madrid: Eds: Marcial Pons.

Puig, S.M. (1976). Introducción a las bases del derecho penal. Concepto y Método. Barcelona, España: Barcelona Bosch.

Roxin, C. (1997). Derecho Penal. Parte general I: Fundamentos. La estructura de la teoría del derecho. España, Madrid: Eds: Civitas. 